\title{
Rancang Bangun Sistem Pengukuran Volume Air Otomatis dalam Gelas menggunakan Konveyor Berbasis Mikrokontroler Atmega 2560
}

\author{
Karya Suhada $^{1}$, Yudiana ${ }^{2}$, David Alfa ${ }^{3}$ \\ 1,2,3 Teknik Informatika, STMIK Rosma, Karawang \\ Email: karya@rosma.ac.id
}

\begin{abstract}
This study aims to design and realize a dispenser device that can facilitate the user in taking drinking water. The automatic dispenser is designed in two stages, namely, hardware design and software design. This tool uses an ultrasonic sensor, an infrared sensor as a glass detector, a servo motor that can make it easier for the user to open and close the dispenser faucet so that there is little chance of water spills and the conveyor makes it easier for the user to no longer hold the glass. The results of this study indicate that all components and sensors used in this dispenser will work according to the commands that have been programmed in the ATMega 2560 Microcontroller. Testing of the tool is carried out with 5 experiments, namely by filling the glass with hot water and warm water, the test results show that the dispenser is able to work as expected.
\end{abstract}

Keywords: Atmega 2650, Automatic Dispenser, Microcontroller

\begin{abstract}
Abstrak
Penelitian ini bertujuan untuk merancang dan merealisasikan sebuah alat dispenser yang dapat memudahkan pemakainya dalam pengambilan air minum. Dispenser otomatis dirancang dengan dua tahap yaitu, perancangan hardware dan perancangan software. Alat ini menggunakan sensor ultrasonic, sensor infrared sebagai pendeteksi gelas, motor servo yang dapat memudahkan pemakai dalam membuka dan menutup keran dispenser sehingga kecil kemungkinan adanya tumpahan air dan konveyor agar mempermudah pemakai sehingga tidak lagi memegang gelas. Hasil dari penelitian ini menunjukkan bahwa seluruh komponen dan sensor yang digunakan pada alat dispenser ini akan bekerja sesuai perintah yang telah diprogram dalam Mikrokontroler ATMega 2560. Pengujian alat dilakukan dengan 5 kali percobaan, yaitu dengan mengisi gelas dengan air panas dan air hangat, hasil pengujian menunjukkan bahwa dispenser tersebut mampu bekerja sesuai dengan yang diharapkan.
\end{abstract}

Kata Kunci: Atmega 2650, Dispenser Otomatis, Mikrokontroler

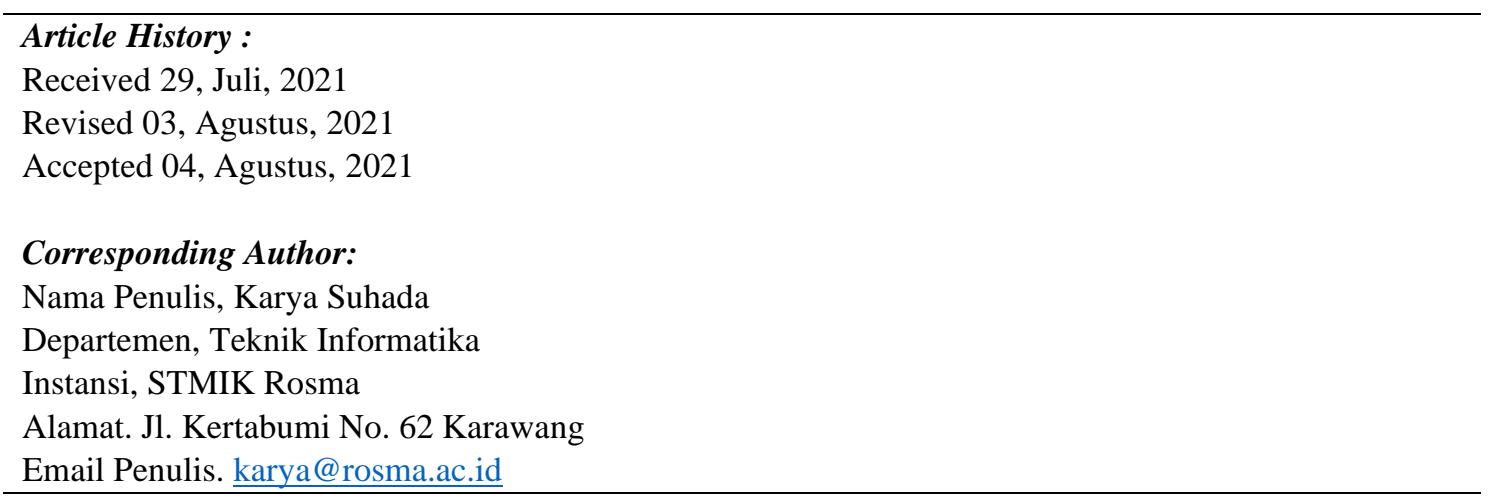




\section{Pendahuluan}

Dispenser merupakan teknologi buatan manusia sebagai tempat penampung air minum yang berguna untuk membantu manusia dalam penempatan maupun pengambilan air minum. Dispenser yang beredar dipasaran Indonesia saat ini adalah dispenser dengan pilihan air minum panas dan biasa, dengan sebelumnya menekan tombol On untuk menghidupkan sistem pemanas atau pendingin air yang selanjutnya air minum dapat diambil dengan cara membuka kran dispenser air panas atau air normal secara manual sesuai dengan yang dikehendaki.

Dalam rangkaian Dispenser tombol ini digunakan Mikrokontroler AtMega 2560 yang berfungsi untuk mengontrol dan menjalankan program yang telah dibuat agar dispenser dapat berfungsi dengan baik. Penggunaan Mikrokontroler sangat luas, untuk pengendalian di pabrik - pabrik, kebutuhan peralatan kantor, peralatan rumah tangga dan lain-lain. Hal ini disebabkan karna mikrokontroler merupakan sistem mikroprosesor (yang didalamnya terdapat CPU, ROM, RAM dan I/O) yang terpadu pada satu keeping. Selain itu komponennya murah dan mudah didapat di pasaran. Penulis merasa bahwa perkembangan mikrokontroler perlu diketahui oleh semua orang yang berkeinginan masuk dalam dunia elektronika.

Penelitian yang dilakukan oleh R. Singgeta dan R. Rumondor (2018) [1], penelitian yang dilakukan oleh R. Singgeta, P. Manembu dan R. Sangkay (2019) [2] dan R. Listiana dan M. Ghozali (2020) [3] menunjukkan bahwa hasil penelitian ini telah berhasil merancang dispenser otomatis. Hal inilah yang menjadi dasar penulis dalam merancang sistem pengukuran volume air otomatis didalam gelas dengan harapan hasil penelitian ini dapat memberikan pengetahuan bagi pembaca mengenai Dispenser tombol menggunakan konveyor berbasis mikrokontroler yang dilakukan pada penelitian ini.

\section{Tinjauan Pustaka}

\subsection{Mikrokontroler Atmega 2560}

Arduino Mega2560 adalah papan mikrokontroler berbasiskan ATmega2560 (datasheet ATmega2560). Arduino Mega2560 memiliki 54 pin digital input/output, dimana 15 pin dapat digunakan sebagai output PWM, 16 pin sebagai input analog, dan 4 pin sebagai UART (port serial hardware), $16 \mathrm{MHz}$ kristal osilator, koneksi USB, jack power, header ICSP, dan tombol reset [4]. ATmega2560 merupakan sebuah mikrokontroler berbasis RISC AVR 8 bit dari Atmel dengan performansi tinggi. Dengan mengeksekusi sejumlah intruksi dalam satu siklus tunggal, perangkat mencapai throughput mendekati 1 MIPS per $\mathrm{MHz}$, menyeimbangkan konsumsi daya dan kecepatan pemrosesan. Perangkat ini mampu mencapai throughput 16 MIPS pada $16 \mathrm{MHz}$ dan beroperasi antara $4.5-5.5$ volt [5].

\subsection{Arduino IDE}

IDE ini merupakan singkatan dari Integrated Development Enviroenment, atau secara Bahasa mudahnya itu merupakan suatu lingkungan yang terintegrasi digunakan untuk melakukan sebuah pengembangan. Arduino IDE menggunakan bahasa pemrograman sendiri yang menyerupai bahasa C. Bahasa pemrograman Arduino (Sketch) ini sudah dilakukan suatu perubahan untuk memudahkan bagi pemula dalam melakukan suatu pemrograman dari bahasa yang aslinya. Sebelum dijual nya kepasaran, IC mikrokontroller Arduino ini sudah ditanamkan suatu program yang bernama Bootlader yang berfungsi sebagai penengah antara mikrokontroller dengan compiler Arduino. Arduino IDE ini dibuat dari bahasa pemrograman JAVA. Arduino IDE ini juga dilengkapi dengan library $\mathrm{C} / \mathrm{C}++$ biasa disebut dengan Wiring yang akan membuat suatu operasi inputan dan outputnya dengan sangat mudah. Arduino IDE ini menunjukkan board yang 
terkonfigurasi beserta dengan $\mathrm{COM}$ port yang digunakan [6].

Sedangkan arduino IDE menurut Ariessanti, dkk (2015:167) [7], IDE adalah sebuah software yang sangat berperan untuk menulis program, meng-compile menjadi kode biner dan mengupload ke dalam memory microcontroller.

\subsection{Liquid Crystal Display (LCD)}

LCD merupakan salah satu perangkat penampil yang sekarang ini mulai banyak digunakan. Penampil LCD mulai dirasakan menggantikan fungsi dari penampil CRT (Cathode Ray Tube), yang sudah berpuluhpuluh tahun digunakan manusia sebagai penampil gambar/text baik monokrom (hitam dan putih), maupun yang berwarna [8].

\subsection{Infrared}

Infra red (IR) detektor atau sensor infra merah adalah komponen elektronika yang dapat mengidentifikasi cahaya infra merah (infrared, IR). Sensor infra merah atau detektor infra merah saat ini ada yang dibuat khusus dalam satu module dan dinamakan sebagai IR Detector Photomodules. Sensor ini dapat bekerja apabila keadaannya low. Jika objek mendekati sensor maka output sensor akan bernilai low [9].

\subsection{Power Supply / Adaptor}

Power Supply atau Adaptor merupakan rangkaian elektronika yang dapat menghasilkan energi listrik atau sebagai sumber energi untuk rangkaian elektronika lainnya. Sumber arus dari power supply adalah arus bolak-balik (AC) dari pembangkit listrik yang kemudian diubah menjadi arus searah (DC). Untuk dapat melakukan hal tersebut power supply memerlukan perangkat yang bisa mengubah arus AC menjadi DC [10].

\subsection{Sensor Ultrasonik}

Sensor ultrasonik adalah sensor yang bekerja berdasarkan prinsip pantulan gelombang suara dan digunakan untuk mendeteksi keberadaan suatu objek atau benda tertentu didepan frekuensi kerja pada daerah diatas gelombang suara dari $20 \mathrm{kHz}$ hingga 2 Mhzterpadu [11].

\subsection{Konveyor}

Menurut Wina Audina Bangun (2018:16) [8] Konveyor adalah bagian umum dari peralatan penanganan material mekanis yang bergerak dari satu lokasi ke lokasi lain. Konveyor terutama berguna dalam aplikasi yang melibatkan transportasi bahan berat atau besar. Konveyor memungkinkan transportasi cepat dan efisien untuk berbagai bahan. Di dalam industri, bahan -bahan yang digunakan kadangkala merupakan bahan yang berat maupun berbahaya bagi manusia. Untuk itu diperlukan alat transportasi untuk mengangkut bahan -bahan tersebut mengingat keterbatasan kemampuan tenaga manusia baik itu berupa kapasitas bahan yang akan diangkut maupun keselamatan kerja dari karyawan adalah satu jenis alat pengangkut yang sering digunakan adalah konveyor yang berfungsi untuk mengangkut bahan- bahan industri yang berbentuk padat.

\section{Metode Penelitian}

Dispenser otomatis dirancang dengan dua tahap yaitu, perancangan hardware dan perancangan software. Perancangan hardware yang terdiri dari beberapa alat dan komponen seperti mikrokontroller ATMEGA2560, Sensor Infrared, Rangkaian power supply diintegrasikan menjadi sebuah sistem. Sistem yang terintegrasikan antara satu dengan yang lain disebut embedded systemyang dapat dilihat dari diagram blok pada gambar dibawah ini.

Jurnal Interkom: Jurnal Publikasi Ilmiah Bidang Teknologi Informasi dan Komunikasi

Volume 16 Nomor 02 Bulan Juli - Tahun 2021 


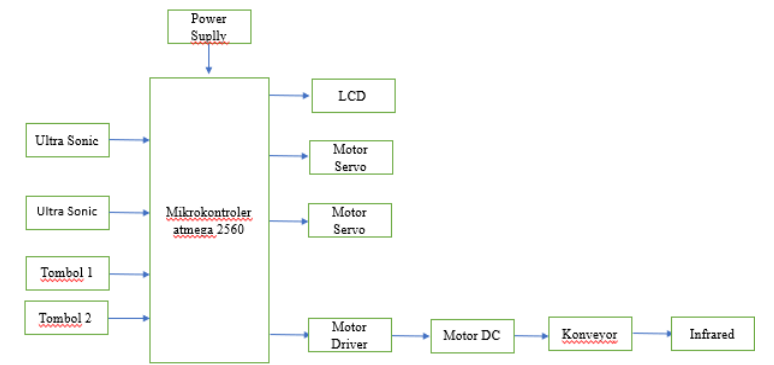

Gambar 1. Diagram Blok Rangkaian

\section{a. Mikrokontroler Arduino Atmega}

Pada rangkaian alat ini digunakan sebagai pusat kendali pada seluruh sensor yang ada semua berhasil pada penelitian ini. Adapun program yang diisikan ke mikrokontroller sebagai berikut.

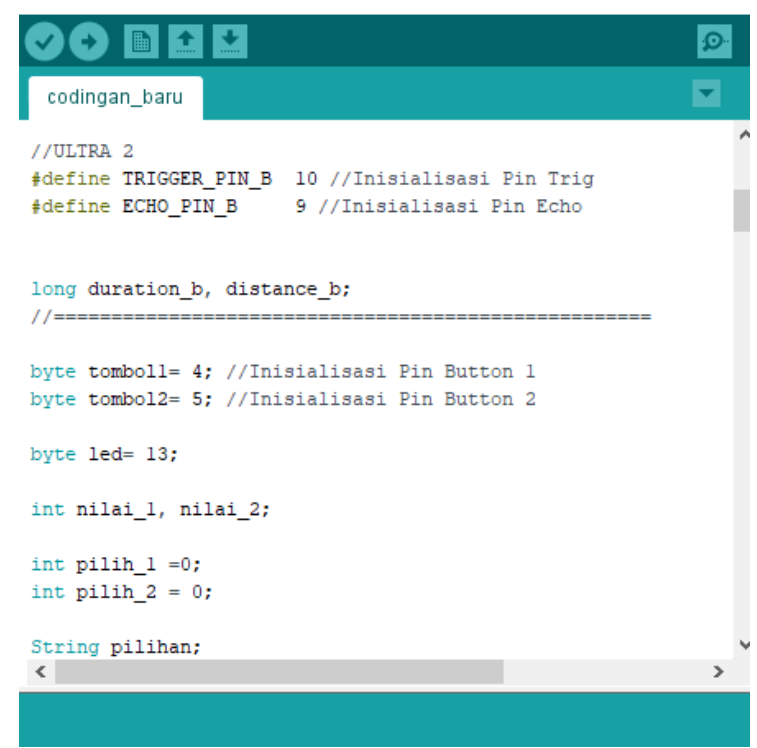

Gambar 2. Program Mikrokontroler Arduino atmega 2560

\section{b. LCD (Liquid Crystal Display)}

Sebuah LCD dot matriks 2 x 16 karakter yang berfungsi sebagai tampilan hasil pengukuran dan tampilan dari beberapa keterangan. LCD dihubungkan langsung ke Port D dari mikrokontroler yang berfungsi mengirimkan data hasil pengolahan untuk ditampilkan dalam bentuk alfabet dan numerik pada LCD.

Berdasarkan keterangan di atas maka kita sudah dapat membuat progam untuk menampilkan karaker pada display LCD.

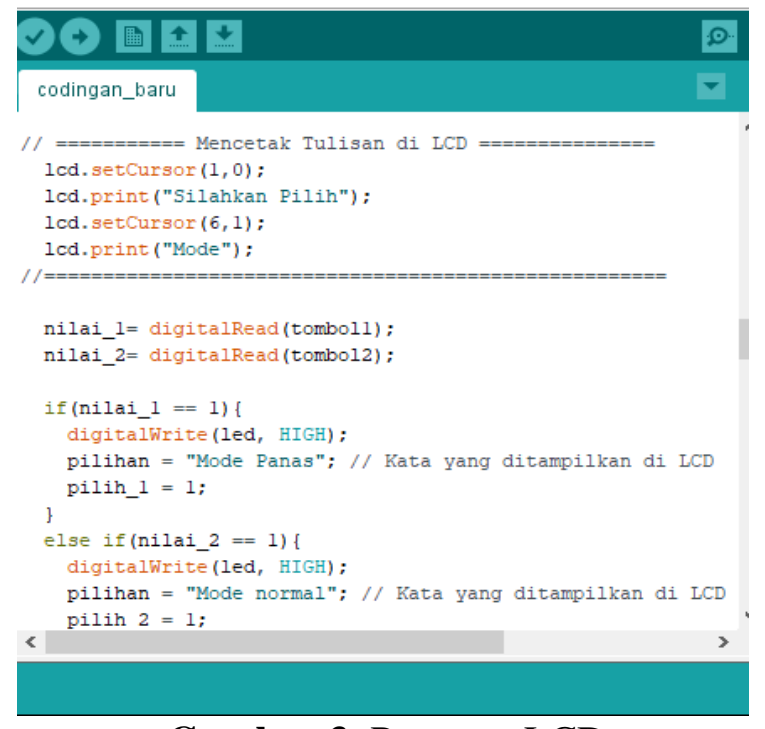

Gambar 3. Program LCD

Adapun hasil dari program adalah sebagai berikut :

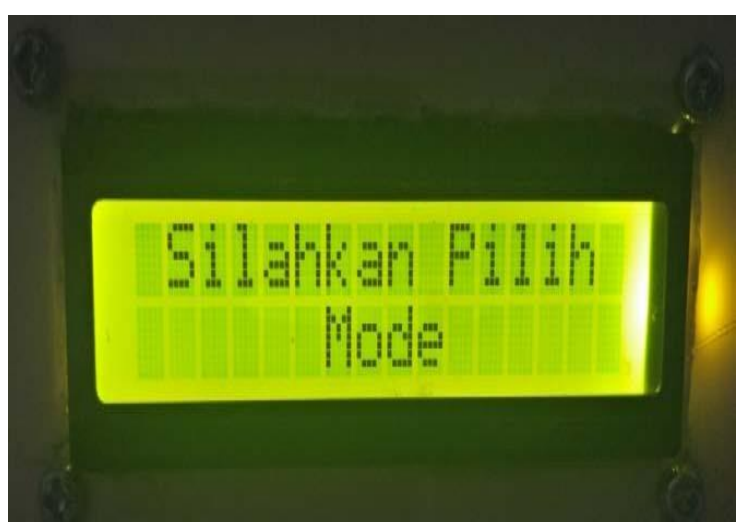

Gambar 4. Hasil LCD

\section{c. Sensor Ultrasonic}

Pada rangkaian alat ini digunakan 2 sensor ultra sonic yang berfungsi sebagai pendeteksi keberadaan gelas untuk membuka kran. Sensor 1 sebagai pendeteksi gelas di bawah kran air panas, sensor 2 sebagai pendeteksi gelas di bawah kran air normal, dari 2 sensor ultrasonic tersebut berhasil berjalan. 


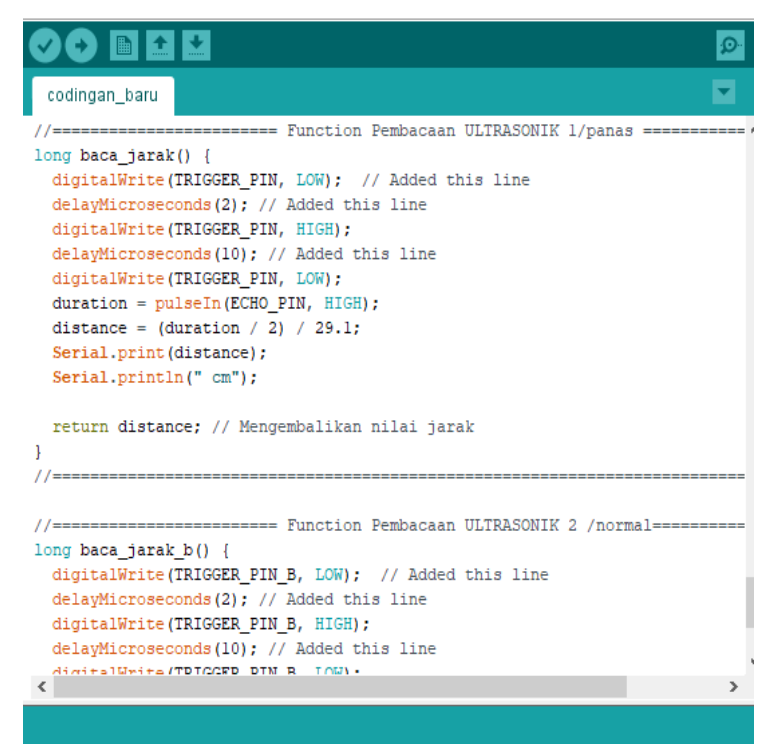

Gambar 5. Program ultrasonic

\section{d. Motor Servo}

Pada alat ini digunakan motor servo yang berfungsi untuk membuka dan menutup kran dispenser berhasil berjalan.

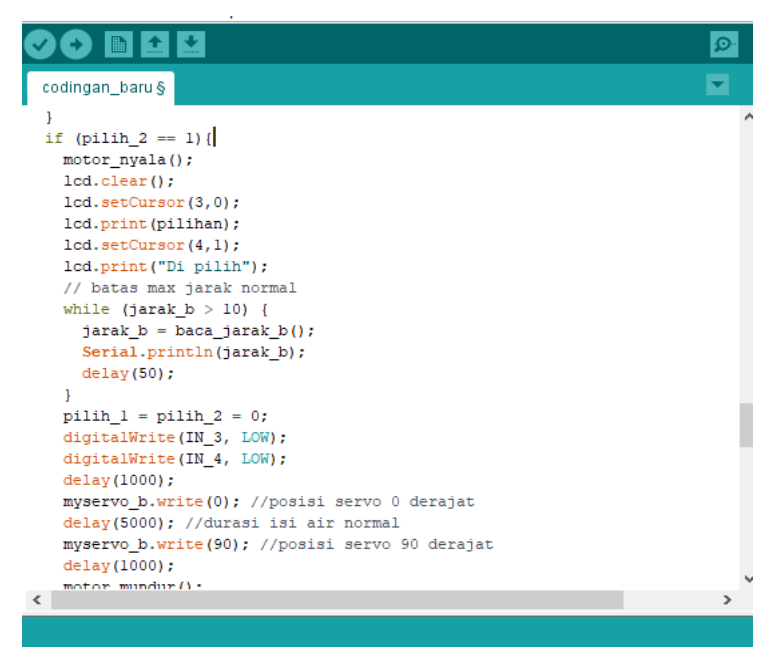

Gambar 6. Program motor servo

\section{e. Motor Driver}

Pada alat ini digunakan Driver motor yang berfungsi untuk mengatur kecepatan motor DC berhasil.

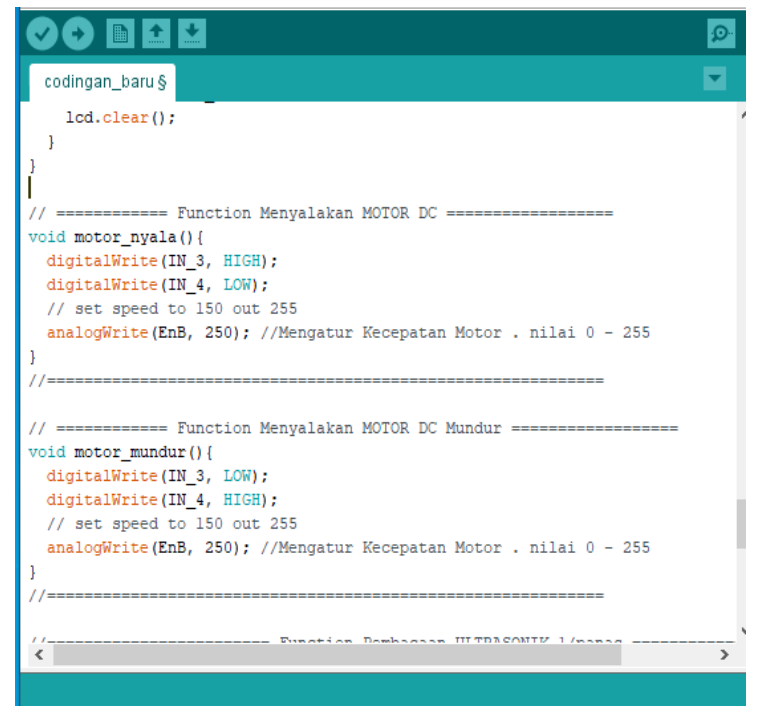

Gambar 7. Program motor driver

\section{f. Motor DC}

Pada alat ini digunakan motor dc yang berfungsi untuk mengantarkan gelas ke ujung dari konveyor berhasil berjalan.

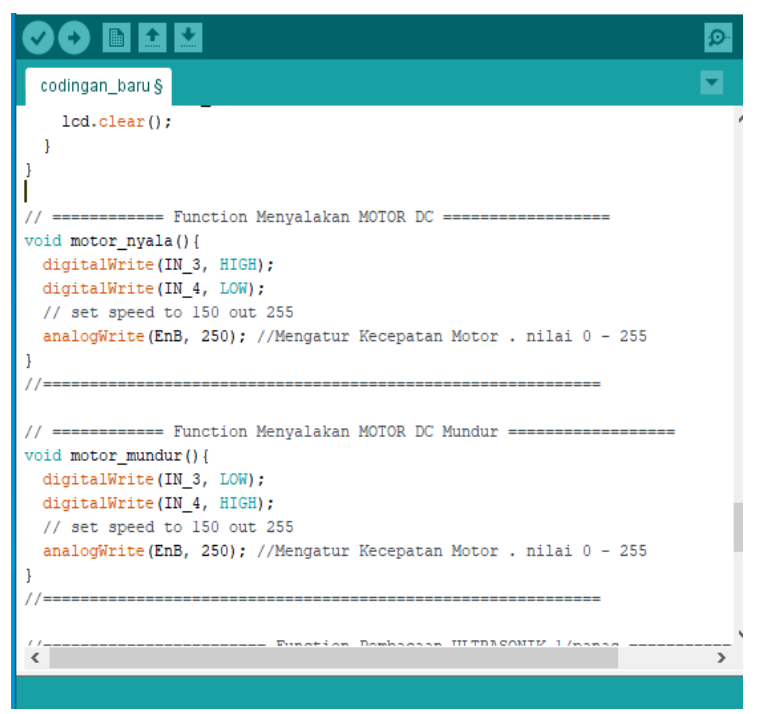

Gambar 8. Program motor dc

\section{g. Konveyor}

Pada umumnya konveyor harganya sangatlah mahal, maka dalam penelitian ini konveyor dibuat dengan menggunakan papan akrilik tipis. 


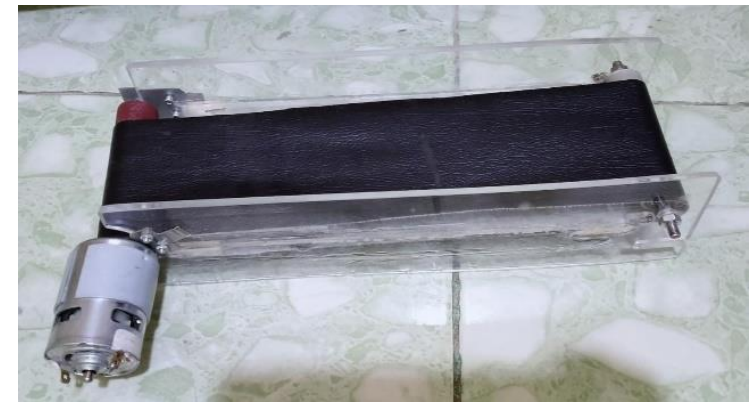

Gambar 9. Konveyor

\section{h. Infrared/Intra merah}

Pada alat ini digunakan sensor infrared yang berfungsi untuk memberhentikan laju dari konveyor berhasil.

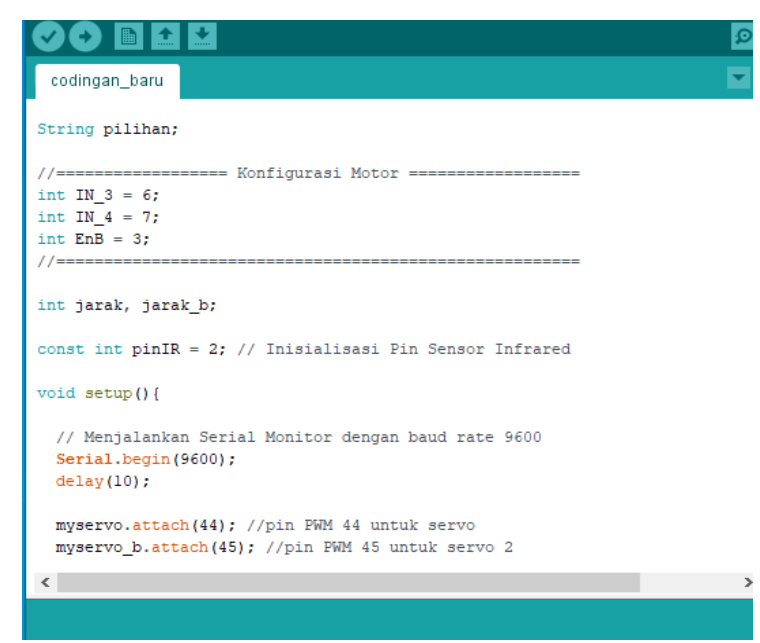

Gambar 10. Program infrared

\section{i. Power Supplay Adaptor (PSA)}

Rangkaian ini berfungsi untuk memberikan supply tegangan ke seluruh rangkaian yang ada. Rangkaian PSA yang dibuat terdiri dari dua keluaran, yaitu 5 volt dan 12 volt, keluaran 5 volt digunakan untuk mensupplay tegangan ke seluruh rangkaian, sedangkan keluaran 12 volt digunakan untuk mensuplay tegangan ke relay. Rangkaian power supplay ditunjukkan pada gambar 4.10 berikut ini :

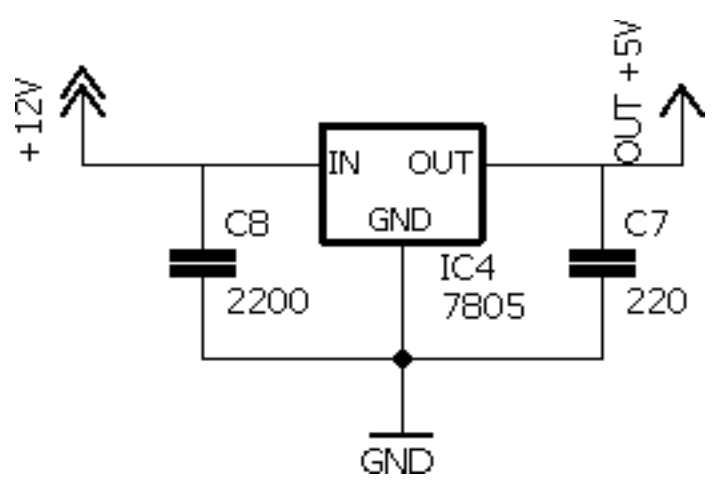

Gambar 11. Rangkaian Power Supply Adaptor (PSA)

\section{Hasil dan Pembahasan}

\subsection{Hasil Perancangan}

Hasil dari perancangan hardware dispenser tombol ini bisa di lihat pada gambar 12. Dispenser tersebut dimodifikasi agar bisa memudahkan dalam pengambilan air minum. Beberapa hardware antara lain mikrokontroler Arduino mega 2560, sensor infrared, sensor ultrasonic, Lcd 16x2, motor servo motor dc dan driver motor, infrared/intramerah, papan konveyor serta power supply dipasang di dalam badan nya dispenser secara teratur. Perangkat hardware tersebut di integrasikan secara satu sistem, sensor ultrasonic dan motor servo sebagai pendeteksi gelas kemudian untuk pendeteksi untuk berhenti nya gelas yaitu sensor infrared sedangkan mikrokontroler Arduino mega 2560 adalah sebagai pusat kontrol/proses pada sistem dispenser tombol ini. Dari hasil perancangan tersebut, mampu memudahkan orang dalam pengambilan air minum. 


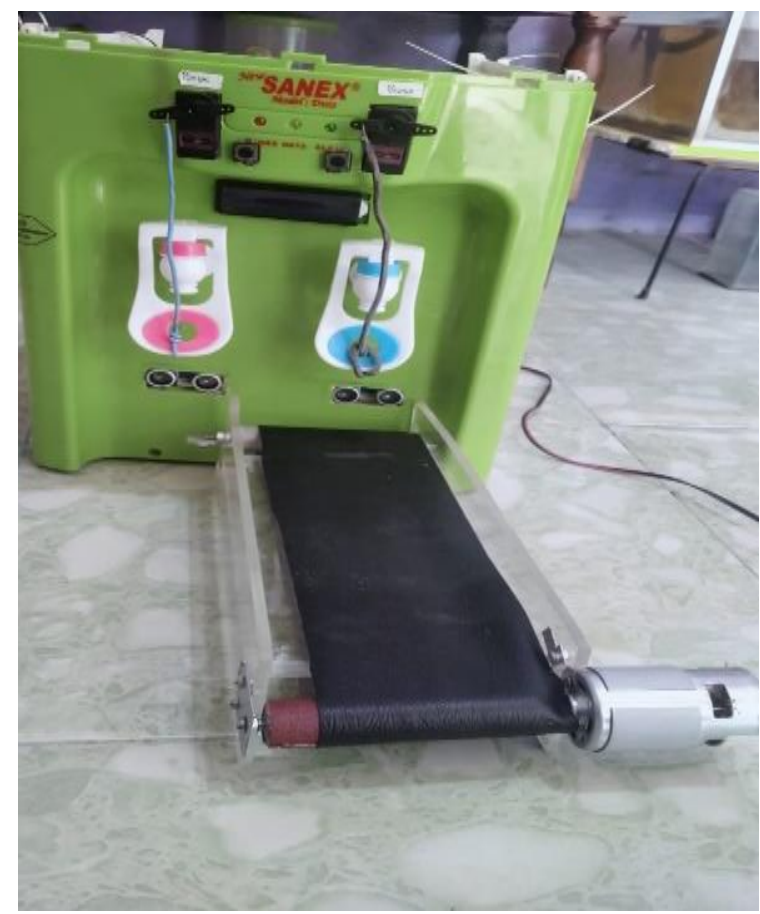

\subsection{Pengujian}

Sistem

Secara

\section{Keseluruhan}

Pengujian ini dilakukan dengan cara menghubungkan semua rangkaian dan kemudian mengeksekusi program yang telah dibuat ke mikrokontroller. Pengambilan data dilakukan dalam 5 kali percobaan dengan jenis air (air panas atau normal) yang berbeda, yaitu:

Gambar 12. Hasil perancangan dispenser

Tabel 1. Percobaan pengisian air ke dalam gelas

\begin{tabular}{|l|l|c|}
\hline \multicolumn{1}{|c|}{ Perintah } & \multicolumn{1}{|c|}{ Keterangan Kerja Alat } & Hasil Kerja Alat \\
\hline $\begin{array}{l}\text { Tekan Tombol pilihan } \\
\text { air panas }\end{array}$ & $\begin{array}{l}\text { Konveyor berjalan membawa gelas } \\
\text { konveyor berhenti saat gelas dibawah kran } \\
\text { air panas kran terbuka dan mengisi air ke } \\
\text { dalam gelas setelah gelas terisi kran tertutup } \\
\text { konveyor berjalan kembali konveyor } \\
\text { berhenti saat gelas terdeteksi di depan } \\
\text { sensor infrared. }\end{array}$ & Berjalan dengan baik \\
\hline $\begin{array}{l}\text { Tekan Tombol pilihan } \\
\text { air hangat }\end{array}$ & $\begin{array}{l}\text { Konveyor berjalan membawa gelas } \\
\text { konveyor berhenti saat gelas dibawah kran } \\
\text { air hangat kran terbuka dan mengisi air ke } \\
\text { dalam gelas setelah gelas terisi kran tertutup } \\
\text { konveyor berjalan kembali konveyor } \\
\text { berhenti saat gelas terdeteksi di depan } \\
\text { sensor infrared. }\end{array}$ & Berjalan dengan baik \\
\hline
\end{tabular}

Tabel 2. Percobaan pengisian air ke dalam gelas

\begin{tabular}{|c|c|c|}
\hline Percobaan & $\begin{array}{c}\text { Air Panas } \\
(\mathbf{s})\end{array}$ & $\begin{array}{c}\text { Air Normal } \\
(\mathbf{s})\end{array}$ \\
\hline 1 & 5.30 & 5.29 \\
\hline 2 & 5.29 & 5.30 \\
\hline 3 & 5.30 & 5.29 \\
\hline 4 & 5.30 & 5.30 \\
\hline 5 & 5.30 & 5.30 \\
\hline
\end{tabular}

\begin{tabular}{|c|c|c|}
\hline Percobaan & $\begin{array}{c}\text { Air Panas } \\
(\mathbf{s})\end{array}$ & $\begin{array}{c}\text { Air Normal } \\
(\mathbf{s})\end{array}$ \\
\hline Rata-rata & $\mathbf{5 . 3 0}$ & $\mathbf{5 . 3 0}$ \\
\hline
\end{tabular}

Keterangan :

Percobaan pada tabel 2 dilakukan untuk mengetahui bahwa seluruh alat yang di gunakan bekerja dengan baik, sehingga gelas terisi air dengan durasi yang sesuai 
dengan perintah pada program, dan volume air $100 \mathrm{ml}$ setiap gelas.

\section{Kesimpulan}

Berdasarkan penelitian yang dilakukan penulis maka penulis dapat menarik kesimpulan sebagai berikut:

a. Dari hasil pengujian yang telah dilakukan dapat diketahui bahwa alat dispenser otomatis ini berjalan dengan baik, dikarenakan waktu pegisian air yang relatif sama yaitu 5,30 sekon per $250 \mathrm{ml}$ setiap gelas.

b. Dengan alat ini manusia dipermudah dalam pengambilan air minum. Hanya dengan menekan tombol pilihan jenis air, gelas telah terisi air secara otomatis tanpa menyentuh kran lagi lalu di antarkan menggunakan konveyor.

\section{Saran}

Berikut ini merupakan saran dari penelitian peneliti, sebagai berikut:

a. Untuk penelitian selanjutnya, diharapkan agar alat ini mampu mengisi air kedalam gelas dengan berbagai ukuran.

b. Untuk penelitian selanjutnya, diharapkan agar ada fitur pemberitahuan jika air sudah habis.

\section{Daftar Pustaka}

[1] R. L. Singgeta and R. Rumondor, "Rancang Bangun Dispenser Otomatis Menggunakan Sensor Ultrasonik Berbasis Mikrokontroller Atmega2560," J. Ilm. Realt., vol. 14, no. 1, pp. 31-36, 2018, doi: 10.52159/realtech.v14i1.113.

[2] R. L. Singgeta, P. D. K. Manembu, and R. G. Sangkay, "Implementasi Teknologi Rfid Pada Dispenser Air Minum," J. Elektro, vol. 12, no. 1, pp. 23-32, 2019.

[3] R. Listiana and M. H. Ghozali, "Rancang Bangun Alat Penyeduh Minuman Sachet Otomatis Pada
Dispenser Air Dengan Kontrol Arduino Mega 2560," TEDC, vol. 14, no. 3, pp. 272-278, 2020.

[4] M. Majid, "Implementasi arduino mega 2560 untuk kontrol miniatur elevator barang otomatis," Skripsi, p. 76, 2016.

[5] T. U. Anastasia, A. Mufti, and A. Rahman, "Rancang Bangun Sistem Parkir Otomatis Dan Informatif Berbasis Mikrokontroler Atmega2560," Kitektro, vol. 2, no. 1, pp. 29-34, 2017.

[6] N. Syafitri, A. Zarkasi, and R. Passarella, "Rancang Bangun Robot Quadruped Berbasis Arduino," $J$. Ilmu Komput. dan Teknol. Inf., vol. 10, no. 2, pp. 34-37, 2018.

[7] H. D. Ariessanti, M. Martono, and J. Widiarto, "Sistem Pembuangan Sampah Otomatis Berbasis IOT Menggunakan Mikrokontroler pada SMAN 14 Kab.Tangerang," CCIT J., vol. 12, no. 2, pp. 229-240, 2019, doi: 10.33050/ccit.v12i2.694.

[8] W. A. Bangun, "Dispenser Otomatis Menggunakan Konveyor Berbasis Mikrokontroler Atmega 8535," Mat. Dan Ilmu Pengetah. Alam Univ. Sumatera Utara, pp. 1-58, 2018.

[9] M. Faisal and R. W. Arsianti, "Sistem Kran Air Otomatis Menggunakan Sensor Infrared Ajdustable," $J$. Elektr. Borneo, vol. 6, no. 1, pp. 20 24, 2020.

[10] Wildan, A. Romadhona, and A. Hernita, "Irigation Monitoring Control Untuk Tanaman Hidroponik Dengan Metode Nft Menggunakan Arduino Berbasis SMS Gateway," $e$ Jurnal JUSITI (Jurnal Sist. Inf. dan Teknol. Informasi), vol. 9, no. 1, pp. 77-85, 2020, doi: 10.36774/jusiti.v9i1.645.

[11] S. A. Kurniatuty and K. A. Widodo, "Rancang Bangun Sistem Kontrol Pakan Ikan dan Kekeruhan Air yang Dilengkapi Dengan Monitoring 
Kualitas Air Berbasis Internet of Things ( IoT )," Informatika, vol. 02, no. 01, pp. 1-5, 2015.

[12] P. D. Sugiyono, Metode Penelitian Kuantitatif, Kualitatif, dan $R \& D$. Bandung: Alfabeta, 2018.

[13] H. Nawawi, Metode Penelitian Bidang Sosial. Yogyakarta: Gajah Mada University Press, 2012. 